\section{INVERSION OF THE UTERUS.}

To the Elitor of THE LANCET.

SrR,--The perusal of Mr. Death's communication, reported in your journal of last week, has induced me to narrate the particulars of a case occurring in my practice some time since.

Mrs. C-, aged forty-tive, was taken in labour with her fifteenth child. The midwife in attendance was her mother. The presentation and birth of the chill were natural, but un due traction had been applied to the funis, and on my arrival within five minutes of the accident, I found the uterus inverted, with the placenta firmly adherent to it, and lying externally to the vulva. There had been but slight hæmorrhage. I therefore instantly determined on detaching the placenta, and with my left hand, half closed, doubled up like a cone, 1 pressed steadily against the most depending part of the organ, and the reduction was speedily effected. Four ounces of brandy were administered directly, and she rallied at once from the shock. Subsequently no adverse symptoms arose, and in a few days the patient was convalescent.

In this instance, the favourable termination of the case was mainly attributable to the prompt aid afforded.

I am, Sir, your obedient servant

Bethnal-green-road, Oct. $1861 . \quad$ JAMES RoLPH, M.R.C.S.

\section{LIQUOR HYDRARGYRI PERNITRATIS IN GONORRHCEA. \\ To the Editor of The LANCET.}

SiR, - Since the pubiication in your journal of Oct. 12th of my report of Mr. Childs' treatment of gonorrhoa by the above remedy, I have had several letters from members of the profession inquiring the strength of the solution used. May I therefore state, for the benefit of those interested, that the liquor hydrargyri pernitratis used at the Metropolitan Free Hospital is obtained of Darby and Godsen, wholesale chemists, 140, Leadenball-street, and contains twelve grains of the solid hydrargyri pernitratis in the fluid drachm.

I am, Sir, yours very truly,

Metropolitan Free Hospital, Oet. 1861. JoHN WAKNER.

\section{PARISIAN MEDICAL INTELLIGENCE.} (FROM OUR SPECIAI CORRESPONDENT.)

M. Bouchur has drawn the attention of the Academy of Sciences to certain facts regarding the mortality of infants, which, though in themselves almost self-evident, are of quite sufficient importance to bear repetition. A careful examination of the hospital archives, embracing a period of twenty years, (from 1839 to 1859 , ) has enabled him to make the following deductions regarding the causes which affect the life of the foundling or of the offspring of the poorer inhabitants of Paris, whom want has compelled to confide their children to the care of the State. The present average of infant mortality in France, if a comprehensive view of all classes of society be taken, is one-sixth, instead of one-fourth as formerly, during the first year of life, deaths being more frequent in the case of the male than in that of the female sex. The proportion of children who tie in early life is far greater in the lower classes than in the higher. Iufant mortality generally is more considerable during the winter than at any other season, and M. Bouchut regards the exposure of young children to a low temperature, rendered inevitable by the existing rules of registration, as highly dangerous. I may here mention, parer thetically, that the law requires that all infants shall be taken to the office of the mayor within three days after birth for the purpose of being registered. In the case of those foundlings who are given in charge to nurses resident in the country, the ratio of mortality, as computed by M. Bouchut, is 11 per cent. during the first ten days of life, and 55 per cent. during the first year-a proportion considerably augmented when the infant is reared by hand. Residence in the immediate neighbourbood of Paris is found to be far more fatal to children in early life than removal into the surrounding departments-a circumstance accounted for by the overcrowded state of the population, and by the usual exten. sion to the suburbs of the various epidemic diseases of the capital.
M. Maisonneuve has just laid before this Academy six fresh cases of removal of necrosed bone by the subperiosteal method, in all of which complete repair of the osseous tissue had followed the operation. In one of the instances referred to by this surgeon, the patient, a young girl living in a remote department (Ardennes), had travelled all the way to Paris for the purpose of having "a new bone put into her hand." The village schoolmaster, she maintained, had assured her that repairs of this nature were undertaken commonly enough in this capital. Complete extirpation of the necrosed bone (the fifth metacarpal) was performed on the 3rd of May, and, thanks to a good and vigorons constitution no doubt, by the end of the same month the girl was able to return home, with the object of her journey completely realized, and a new bone in place of the old one.

M. Demarquay likewise related the case of a young man, from whom he removed five inches of femur by the same method, with a like success.

A note addressed by M. Landionzy, of Rheims, to the Academy of Medicine, and read at Tuesday's meeting, contains some observations of interest on the subject of ægophony, and of its value as a diagnostic in pleurisy. The author states that the prevalence of Laënnec's views regarding this particular sound, and (as be believes) their practical fallacy, have induced him to publish the results of his clinical researches in connexion with this point. He remarks that in some cases agophony, during the operation of tapping the chest, angments during the escape of the fluid, and remains well marked for several days after its evacuation; but that in others the sound diminishes as the chest collapses, and ceases entirely at the conclusion of the operation. Hence he argues that the existence of ægophony indicates neither the presence of effusion, nor its abundance, nor its limits, but purely and solely a particular condensation of the lung, due to the compression of the organ by the liquid as poured out in the first place, and occasionally persisting after its withdrawal. The effusion therefore is only an indirect cause of the abnormal sound. When the lung is compressed by the fluid contained in the pleural cavity, and no dense false mem. branes exist, the performance of paracentesis may abolish at once both the symptom of xgophony and that of dulness on percussion, the lung immediately regaining its normal capa. city; but if false membranes of a solid and unyielding cha. racter have been formed, then the expansion of the organ is impeded, and agophony will persist. "External compression," continues M. Landouzy, "produces æegophony in pleurisy, just as the internal compression in pneumonia produces bronchophony; and so long as the condensation of the lung in the for. mer disease continues, so long does the sound, which has been heretofore thought to be inseparable from the presence of liquid, continue to be heard."

M. Mirault (d'Angers), a corresponding member of the Academy, subsequently read a communication on a question which eighteen years ago formed the subject of a very animated debate between $M$. Malgaigne and the ophthalmic practitioners of France-namely, capsular cataract. In 1843 the existence of capsular cataract was denied in the most formal manner by M. Malgaigne; and although the result of the prolonged discussion which ensued was to prove that this assertion was erro. neous, yet it was only then for the first time ascertained that this particular pathological condition is excessively rare. The particular object held in view by M. Mirault did not seem, however, so much to be the confirmation of this now ascertained fact, but rather the impressing upon the mind of his hearers - first, the occasional occurrence of secondary capsular cataract; secondly, its amenability to well-directed treatment; and lastly, the possibility of applying the same measures with success in the case of the primitive form of capsular opacity. The treatment recommended in the memoir differs little from that usually resorted to in England for the purpose of quelling intra-ocular inflammation and hastening absorption, the plan being bleeding, general and local, purgatives, cutaneous revulsives, and external applications of belladonna or mercurial friction on the brow and temple. By such means the author of the essay states that he has been enabled to restore vision in 11 out of 14 cases.

The largest and best organized hospital laundry in Paris is that of the Salpetrière. So well managed, indeed, are the various processes contrived for the purification of linen in that establishment, that it has become one of the lions of the capital. There is some intention, so I am given to understand, of increasing the present building, and of augmenting the hands employed, in order to convert this laundry into a central wash. house for the benefit of all the Paris hospitals. There exist already a general bakehouse, pharmacy, and cellar; and as the 